\section{Biolumineszenz, allgemein}

T. Arndt

Bioscientia Institut für Medizinische Diagnostik $\mathrm{GmbH}$, Ingelheim, Deutschland

\section{Englischer Begriff bioluminescence}

Definition Biolumineszenz ist von lebenden Organismen erzeugte Lumineszenz (IUPAC 2014).
Beschreibung Die Biolumineszenz ist eine Sonderform der $\checkmark$ Chemolumineszenz und diese eine Form der $>$ Lumineszenz.

\section{Literatur}

IUPAC (2014) www.iupac.org/goldbook/L03641.pdf. Zugegriffen am 21.08.2017 